\title{
Escrituras de adopción o prohijamiento de expósitos \\ de la Inclusa de Madrid (1700-1852)
}

\section{Requirements of adoption of foundlings in the Inclusa of Madrid (1700-1852)}

\author{
Raquel MEDINA PLANA \\ Profesora Titular de Historia del Derecho \\ Departamento de Historia del Derecho. Facultad de Derecho \\ Universidad Complutense de Madrid \\ rmedina@der.ucm.es
}

Recibido: 31 de otubre de 2014

Aceptado: 2 de diciembre de 2014

\begin{abstract}
RESUMEN
Los Fondos de la Inclusa del Archivo Regional de la Comunidad de Madrid conservan cientos de escrituras notariales de adopción o prohijamiento de expósitos, que demuestran la vitalidad de la práctica adoptiva durante la Edad Moderna y comienzos de la Contemporánea, y contradicen la tesis de la historiografía tradicional, que señala la desaparición de la institución de la práctica de la época. En este trabajo se realiza un análisis descriptivo de la estructura y las principales características de estos instrumentos notariales, plenamente formales y de gran exigencia obligatoria, en una etapa de transición entre el modelo ilustrado y el liberal, fundamental para comprender la evolución de la institución.
\end{abstract}

PALABRAS CLAVE: Adopción, prohijamiento, expósitos, Inclusa de Madrid.

\begin{abstract}
Hundreds of notarial deeds of adoption of foundlings are conserved at the Madrid Regional Archive, demonstrating the vitality of the practice all along the Modern Age and early Contemporary Age. Its same existence contradicts the traditional historiography thesis, which indicates the disappearance of the adoptive institution at the time. This paper presents a descriptive analysis of the structure and the main characteristics of these notarial instruments, which include a diversity of fully formal and mandatory requirements. Performed in a transitional stage between the enlightened and the liberal models, their knowledge is critical for the understanding of the evolution of the institution.
\end{abstract}

KEYWORDS: Adoption, foundlings, Inclusa de Madrid.

\section{RÉSUMÉ}

Centaines d'actes notariés d'adoption d'enfants trouvés sont conservées dans les fonds de la Inclusa du Archive Régional de Madrid, témoignant de la vitalité de la pratique de l'adoption durant les ages moderne et contemporaine. Cela contredit la thèse de l'historiographie traditionnelle, qui indique la disparition de l'institution dans la pratique de l'époque. Cet article présente une analyse descriptive entièrement formelle de la structure et les principales caractéristiques de ces actes notariés, qui seraient 
d'une haute exigence obligatoire. Leur appartenance à une phase de transition entre le modèle des Lumières et le modèle libéral se revele essentielle pour comprendre l'évolution de l'institution.

MOTS CLÉ : Adoption, enfants trouvés, Inclusa de Madrid.

SUMARIO: Introducción. El supuesto eclipse de la adopción y los prohijamientos de expósitos. ¿Adopción o prohijamiento? La indistinción terminológica. Las escrituras de prohijamiento o adopción. La progresión cuantitativa. La estructura de las escrituras: 1. El proemio. 2. El memorial de solicitud. 3. El otorgamiento. 4. Las cláusulas. 4.1. El compromiso de cuidado, alimento y educación. 4.2. Las obligaciones patrimoniales. 4.2.1. La institución de herencia. 4.2.2. El compromiso de dote. 4.3. Condiciones. 5. Garantías. 6. Renuncias. 7. Autorización. Conclusiones.

\section{Introducción. El supuesto eclipse de la adopción y los prohijamientos de expósitos}

El enorme auge de la adopción en las últimas décadas la ha hecho objeto de una inusitada atención por parte de juristas y científicos sociales. No siempre ha sido así, ni mucho menos: la amplitud de su exposición y aceptación social actual puede hacernos olvidarque esta institución, compleja e interesante como pocas, ha sido tradicionalmente contemplada con una cierta reserva y una paralela falta de interés por parte de juristas e historiadores. Debido a ello, la historia de la institución jurídica de la adopción presenta todavía hoy numerosas lagunas y contradicciones; carencias de conocimiento histórico que, como en tantos otros casos, se han querido proyectar en la propia institución. La historiografía jurídica subraya así una evolución llena de discontinuidades y transfiguraciones, hecha de «larguísimos eclipses» y «singulares renacimientos», cuyo relato viene a ser, a muy grandes rasgos, el siguiente: tras su apogeo en la Antigüedad y una muy posible pero básicamente desconocida continuidad visigoda, durante la Edad Media y la Moderna, la institución desaparecería no tanto del ordenamiento — su regulación se recoge en las Partidas así como en algunos fueros-como de la práctica; se abriría así un enorme periodo de oscuridad o latencia de la institución, que no se rompería hasta su reaparición contemporánea, en la segunda mitad del pasado siglo $\mathrm{XX}^{1}$.

\footnotetext{
${ }^{1}$ Así aparece caracterizada recientemente en la perspectiva romanista de L. Rodríguez Ennes, "Eclipse y renacimiento de la adopción en su devenir histórico", Revista General de Derecho Romano, $\mathrm{n}^{\circ} 13$, 2009, y "La adopción romana: continuidad y discontinuidad de un modelo", Dereito, vol. 18, n 1, 2009, pp. 115-134, en donde afirma que la institución "se desvanece con la caída del Imperio [romano] y, tras 1.500 años de ostracismo, no vuelve a renacer hasta el siglo pasado". La misma idea de discontinuidad aparece en su libro Bases jurídico-culturales de la institución adoptiva, Santiago de Compostela, 1978. Esta tesis no es exclusiva de los romanistas, sino que también es en buena medida compartida por los historiadores del derecho - necesario es decir que no muy numerosos- que se han acercado a esta institución. Es el caso de A. Otero Varela, "La adopción en la historia del derecho español”, Dos estudios histórico-jurídicos, Roma-Madrid, 1955, pp. 83-146 (también recogido en Estudios histórico-jurídicos, vol. 2 (Derecho privado), 2005, pp. 9-92; del mismo autor, "Sobre la realidad histórica de la adopción",
} 
Esta postura historiográfica puede retrotraerse a los planteamientos dogmáticos de los codificadores. Cuando éstos se enfrentan a la duda de si incluir o no a la institución en el Código, la postura mayoritaria se abonaría a la idea de desaparición: conocido es el comentario de García Goyena sobre la misma: No está en nuestras costumbres. Si finalmente la adopción aparece en el Proyecto de Código, y a la postre en el Código mismo, habría sido tan sólo por el mismo impulso inercial que la habría mantenido también en toda la legislación histórica.

Para defender esta tesis de la desaparición de la adopción del ámbito de la práctica fue necesario que los codificadores dieran la espalda a una práctica adoptiva muy concreta y determinada: las adopciones o prohijamientos de expósitos. Una práctica ésta que gozó de una contrastada vitalidad durante la época moderna, alcanzando en ciertas épocas, unas dimensiones más que considerables², y que, si bien fuertemente

AHDE, 1957-1958, pp. 1.143-1.149; M. Bueno Salinas, "La adopción en la Hispania Romana y Visigoda", Initium: Revista catalana d'historia del dret, 2, 1997, pp. 623-636. En Iberoamérica: M.I. Seoane, "Crianza versus adopción en el Buenos Aires colonial: estudio realizado sobre la base de protocolos notariales", Actas y Estudios del IX Congreso del Instituto Internacional de Historia del Derecho Indiano, Madrid, 1991, vol. 2, t. II, pp. 161-182.

${ }^{2}$ De ello nos viene dando noticia, en las últimas décadas, la Historia Social: el trabajo de Álvarez Santaló sobre los expósitos sevillanos señalaba que las adopciones alcanzaron un promedio del $10 \%$ sobre el número total de expósitos durante el siglo XVII, con picos muy superiores, hasta el $21 \%$ alcanzado en 1680; este autor resalta la persistencia del fenómeno en los siglos posteriores, aunque ya sin alcanzar esas frecuencias (L. C. Álvarez Santaló, Marginación social y mentalidad en Andalucía Occidental: expósitos en Sevilla, 1613-1910, Sevilla, 1980, pp. 104-105). Las incursiones de autores posteriores han confirmado la persistencia de esta práctica, así como su disminución a partir del siglo XVIII, en establecimientos de toda la geografía española: véase, en la estela de la obra de Álvarez Santaló, los estudios de R. Fresneda Collado y R. Elgarrista Domeque, "Aproximación al estudio de la identidad familiar: el abandono y la adopción de expósitos en Murcia (1601-1721)”, en F. Chacón, (ed.): Familia y sociedad en el Mediterráneo occidental: siglos XV-XIX, Murcia, 1987, pp. 93-116; E. Gómez Martínez, Los niños expósitos de Andújar, Córdoba, 1987; M. Vallecillo, Política demográfica y realidad social en la España de la Ilustración. La situación del niño expósito en Granada (1753-1814), Granada, 1990; A. Tarifa Fernández, Marginación, pobreza y mentalidad social en el Antiguo Régimen: Los niños expósitos de Úbeda (1665-1778), Granada, 1994; M.D. Cid Pérez, "Veinte años de expósitos. Ceuta 1746-1767", Cuadernos del Archivo Municipal de Ceuta, n. ${ }^{\circ} 10,1996$, pp. 180 y ss.; A. Tarifa Hernández, "Aproximación a la práctica del prohijamiento en la Casa-Cuna de Úbeda (1665-1788)", en A. Rodríguez Sánchez y A. Peñafiel Ramón (eds.), Historia de la Familia. Una nueva perspectiva sobre la sociedad europea. Seminario Familia y Élite de Poder en el Reino de Murcia, siglos XV-XIX, Murcia, 1997 (pp. 81-92); M.T. López Beltrán, "El prohijamiento y la estructura oculta del parentesco en los grupos domésticos malagueños a finales de la Edad Media e inicios de la Edad Moderna (Aportación a su estudio)", en M. ${ }^{a}$ B. Villar García (coord.): Vidas y recursos de mujeres durante el Antiguo Régimen, Málaga, 1997, pp. 49-77; M.P. de la Fuente Galán, Marginación y pobreza en la Granada del siglo XVIII: los niños expósitos, Granada, 2000; D. López Viera, El niño expósito en Huelva y su tierra durante el Antiguo Régimen, Huelva, 2004; A.M. Rodríguez Martín, "El destino de los niños de la inclusa de Pontevedra, 1872-1903”, Cuadernos de estudios gallegos, 55, no 121, 2008, pp. 353-388; J.J. Iglesias Rodríguez: "El prohijamiento o adopción en la Edad Moderna: ley, práctica y doctrina", en F. Núñez Roldán (dir.), La infancia en España y Portugal: siglos XVI-XIX, 2011, pp. 111-132, pág. 120; M. López Vegas, "La adopción a expósitos a través de los fondos notariales. La casa cuna de Antequera (1667-1800)”, comu- 
vinculada —y tal vez ahí esté la razón del rechazo—al ámbito caritativo y beneficial, no carecía de manifestaciones civiles y solemnes.

Sin entrar aquí en las razones - prejuicio social o prurito técnico-que motivaron que esta práctica no fuera tomada en cuenta en absoluto por los codificadores, lo cierto es que la postura dogmáticafue seguida fielmente por la historiografía jurídica posterior, que va a convertir en un lugar común historiográfico la citada tesis del «eclipse» medieval y moderno de la adopción, convenientemente aliñada con una falta casi total de aprecio para con las prácticas adoptivas de expósitos. Cuando llegado el momento esta historiografía es requerida, a mediados del siglo XX, por el despegue de la práctica adoptiva, las monografías dedicadas a la institución seguirán partiendo, como hemos visto, de la tesis de la desaparición de la adopción e ignorando de forma casi absoluta la práctica del prohijamiento de expósitos. En las contadas excepciones en que esas exposiciones históricas toman en consideración el prohijamiento de expósitos, éste aparecerá higiénicamente separado de la adopción, dando por sentado que se trata de situaciones diferentes, sólo muy parcialmente asimilables ${ }^{3}$.

nicación presentada en el Congreso Internacional Familias e Individuos: Patrones de Modernidad y Cambio Social (siglos XVII-XIX), Murcia, 2013.

${ }^{3}$ El historiador Otero Varela constituye una de esas honrosas excepciones de la historiografía, al dedicar un apartado de su exposición monográfica sobre la adopción (J. Otero Varela, La adopción en el Derecho Histórico Español, op. cit., pp. 143 y ss) al prohijamiento de expósitos. En su trabajo alude al mismo como "otra categoría o matiz" de lo que él considera adopción: una "relación cuasi familiar que se constituye por el hecho de recibir como hijos a quienes no lo son por naturaleza". Partiendo de esa consideración general, el prohijamiento de expósitos, recogido en un escueto apartado final, ubicado al margen de su exposición de la evolución histórica de la adopción, queda sin embargo cuidadosamente separado de ésta. Al analizar el tratamiento que le dispensa, resultan muy llamativas, más en un historiador del derecho, las rupturas diacrónicas de su exposición. En primer lugar, la ubicación de este apartado al final del trabajo, lo separa de la evolución expuesta para la adopción, que se detiene en la regulación del Proyecto de Código de 1851. Otero mencionará como "disposición de origen o primera regulación del prohijamiento de expósitos" la Real Cédula de 11 de diciembre de 1796, lo cual es ya en sí mismo, como veremos, una toma de postura sobre la materia; pero esta no es la única ni más importante ruptura de la diacronía en su exposición. Para justificar la separación entre adopción y prohijamiento Otero acude, al principio del apartado, a una sentencia del Tribunal Supremo de 1934, según la cual el uso habría marcado una neta diferenciación entre tres categorías de "relación familiar o cuasi familiar" (sic): la adopción, caracterizada por su forma civil y solemne; el prohijamiento, con forma administrativa y no solemne, pero sí oficial, y por último el "acogimiento", que se distingue por su forma meramente privada y la ausencia de toda garantía. Que un historiador utilice, en 1955, una sentencia de 1934 para justificar la separación entre unas prácticas que se daban, según su propias palabras, al menos un siglo y medio antes de esa fecha, no parece un procedimiento muy correcto. Por otro lado, y como ya hemos hecho notar, la datación del "origen" de esa práctica en 1796 es en sí problemática: al hacer partir su exposición del prohijamiento de expósitos de esa fecha, no sólo obvia el interrogante de cómo se regulaba esta práctica con anterioridad, sino que deja implícita su falta misma de existencia, al menos como práctica regulada ¿Desconocía Otero la relativa frecuencia de esta práctica en los establecimientos de expósitos de toda la Península durante la Edad Moderna? Cierto es que sólo recientemente la investigación histórica ha dirigido su atención sobre este tema, aportándonos datos cuantitativos sobre la relativa importancia de este fenómeno. Aún así, no parece probable que un historiador de su categoría diese por bueno que los prohijamientos de expósitos aparecieran únicamente 
Frente a esa postura, en este trabajo defenderemos la tesis de que el prohijamiento de expósitos no debe entenderse al margen de la evolución de la institución adoptiva, sino que, al menos en algunas de sus manifestaciones, puede decirse que constituye un eslabón de ésta. Las evidencias recogidas, para una horquilla temporal que abarca siglo y medio, desde 1700 a 1850, en forma de varios cientos de escrituras notariales de prohijamiento o adopción de expósitos, perfectamente formales y plenos en su fuerza obligatoria, demuestran que la institución adoptiva estaba viva, y no sólo en el ámbito administrativo.

Nuestro enfoque se querría a medio camino entre el planteamiento eminentemente formalista de la historiografía jurídica y el funcionalismo de la historia del pauperismo, que interesada sobre todo por el objetivo cumplido por la práctica en relación con su objeto central de estudio, la denominada infancia abandonada, asimila sin más el prohijamiento de expósitos a la adopción, contabilizando bajo una misma categoría general prácticas de origen y planteamiento muy diverso ${ }^{4}$. Si nuestro planteamiento puede en cierto modo confluir con esta valoración funcional de los diferentes tipos de adopción por encima de los planteamientos meramente formales, pensamos también que es necesario refinar de alguna forma esa mera equiparación de términos ${ }^{5}$.

a finales del siglo XVIII, cuando surge la regulación ilustrada sobre la cuestión. Sólo queda, por lo tanto, la hipótesis de que tales prohijamientos, si se realizaban, era al margen de toda regulación. De esta forma, Otero logra dos objetivos: 1) confirmar su tesis principal sobre la rareza en nuestras costumbres de las prácticas adoptivas y 2) mantener convenientemente apartado de la formal y solemne adopción civil la práctica, presuntamente vulgar, del prohijamiento de expósitos.

Recientemente, desde un planteamiento civilista y con un punto de vista alternativo que parte del interés por los expósitos, se ha vuelto a afirmar la distinción entre prohijamiento y adopción. El libro de Sevilla Bujalance Los niños expósitos y desamparados en nuestro Derecho histórico, Córdoba, 2001, citado abundantemente por la historiografía no jurídica como apoyo de la distinción radical entre prohijamiento y adopción, no hace sin embargo un tratamiento sistemático del tema, citando únicamente en apoyo de la idea de la separación entre las dos situaciones el hecho de que las Partidas recogen como necesaria la intervención del Juez, mientras que los reglamentos no aluden sino a las Juntas de Beneficencia. Si bien el autor tiene razón en considerar que el texto alfonsino estaba aún en vigor en la época liberal, dar por supuesto que una institución debe mantenerse inamovible y ceñirse estrictamente a una regulación dada cinco siglos atrás, nos parece una postura de extremo formalismo legal, ajena a cualquier consideración histórica. Por otra parte, y como veremos un poco más adelante, tampoco es exacto que "los reglamentos" sólo mencionen a las Juntas. Para terminar, resulta muy interesante que, para apuntalar la distinción mencionada, se dé aquí otro salto diacrónico, recogiendo de nuevo una sentencia del Tribunal Supremo, ésta de 1889, que alude a la falta de requisitos especiales para realizar el prohijamiento de expósitos.

${ }^{4}$ Álvarez Santaló acuña en su trabajo dos tipos diferentes de adopción, que denomina —no se desdeñe lo peyorativo de ambos calificativos- el "legalista" y el "informal" (C. Álvarez Santaló, Marginación social..., pp. 104-105). Este planteamiento, que será seguido por toda la historiografía pauperista en su acercamiento a la práctica adoptiva, procede, en un segundo momento del análisis, a la fusión de ambos tipos en una misma consideración, equiparados por la función cubierta y computándose a efectos estadísticos de manera indistinta.

${ }^{5}$ Por ello, en algún momento, nosotros también nos hemos preguntado, como lo hace A. Tarifa Hernández, “Aproximación a la práctica del prohijamiento...”, p. 89, que "si el dilema era vivir o no vivir ¿no parece lógico dar facilidades al adoptante, y cerrar los ojos después?”. Más adelante, señalando la falta 
Desde nuestro planteamiento resulta obvio que es necesario revisar el desprecio rotundo por las especificidades técnicas, tratadas como meras complicaciones al margen de la realidad y de cualquier funcionalidad. El análisis detallado de tales especifidades será siempre conveniente para evitar tanto la proyección formalista que niega la atención a cualquier práctica que se desvíe de la norma, como la confusión a que puede dar lugar el funcionalismo indiscriminante.Sobre todo porque, más allá de la confirmación de la coexistencia de vías diferentes para la distribución de expósitos en familias, el análisis detenido de estas prácticas, de sus características y el procedimiento que seguían, así como de las razones por las que se optaba por una u otra vía, está por hacer. A ese análisis de enfoque comprensivo pretendemos dedicar un trabajo más amplio; la intención de éste que aquí se presenta no es sino la de examinar las características de ese porcentaje, reducido pero no desdeñable, de prohijamientos de expósitos que siguieron la vía notarial.

\section{¿Adopción o prohijamiento? La indistinción terminológica}

El primer problema con que nos encontramos es el terminológico: ante estos prohijamientos escriturados $i s e$ puede hablar de adopciones, o es necesario limitarse a denominarlos prohijamientos? Empecemos por reconocer que esta cuestión resulta importante únicamente para esa parte de la historiografía de raigambre dogmática, cuya pretensión prioritaria es marcar una separación terminante entre una y otra cosa,

de rigor de los administradores de la Casa-Cuna de Úbeda al oscilar entre la práctica legalista y la informal de entrega de niños, la autora apuntala este mismo criterio, dejando ver más claramente su vinculación con un punto de vista extemporáneo: "Yo creo, conociendo cómo funcionaba aquel pozo de agonía que era la Cuna, que al menos en esto sus responsables acertaban. Facilitar la salida de la Inclusa a algunos niños, aunque fuera por vías poco claras, pudo salvarles la vida" (op. cit., p. 90). La falta de rigor histórico-crítico que se apunta en este párrafo nos hace imposible poder seguir a esta autora cuando en la misma página afirma sucintamente que "la escritura no servía para nada". Dado que, como hemos dicho, nuestro planteamiento coincide parcialmente en esa valoración eminentemente funcional de los actos adoptivos, nos interesa precisar bien en qué lugar disentimos del proceso analítico predominante en esta escuela historiográfica. Nos servimos de nuevo para ello de las muy expresivas palabras de A. Tarifa: la afirmación citada sobre la total inutilidad del instrumento formal de la escritura, se realiza tras constatar la alta frecuencia de casos de devoluciones de niños previamente adoptados (cita seis casos); para la autora, esta abundancia demostraría que "no existe pruebas de que un contrato formal vinculara al expósito estrechamente con su nueva familia, ni parece se sancionara a los que no lo cumplían. La escritura era sólo un papel" (Ibidem).

Con independencia de que nuestra documentación no confirme esa alta frecuencia de devoluciones, y más allá de las necesarias precisiones técnicas que podríamos hacer a esta frase —en el sentido de que la adopción no es, en ningún caso, un "contrato", y que aún si lo fuera su "incumplimiento" no podría generar "sanciones", sino en todo caso responsabilidades-, podríamos estar de acuerdo con la autora en que la vinculación del expósito con sus adoptantes parecía ser sumamente endeble, y también en que la vigilancia sobre el cumplimiento de las obligaciones otorgadas se mostraba escasa o incluso directamente inexistente. Sin embargo, concluir de todo ello que la escritura fuera "sólo un papel" no nos parece consecuente. 
y que utiliza esa distinción para considerar que los prohijamientos deben dejarse al margen de la institución de la adopción. La terminología de la época, desde la de uso común a la más puramente técnica, no abona fácilmente la hipótesis de la distinción entre adopción y prohijamiento. De entrada, es conveniente hacer notar que la fuente jurídica originaria, las Partidas, consideran equivalente uno y otro término: Adoptio, en latin, tanto quier decir en romance, como porfijamiento. ${ }^{6}$

No parece demasiado adecuado, sin embargo, aducir esta asimilación de las Partidas como argumento suficiente para justificar que, en la época que nos concierne, tan distante de ese ordenamiento, tal indistinción siguiera vigente. Como antes dijimos, no es propio de un historiador pensar que, cinco o seis siglos después, la terminología y las características jurídicas de una institución permanezcan inamovibles.

Centrándonos en la época de nuestro análisis, encontramos en primer lugar que la univocidad de ambos términos aparecía ampliamente extendida por aquel tiempo, como se puede ver en la literatura y la prensa escrita ${ }^{7}$. Pero esto, se podría aducir, bien podría ser un uso común, distante del sentido técnico de estos vocablos. Si pasamos a examinar textos del ordenamiento legal de la época, aparece una distinción que parecería todavía justificar esa idea de diferenciación entre un término, el de prohijamiento, de carácter administrativo y otro, el de adopción, que revestiría un carácter más técnico: en efecto, los reglamentos, textos de carácter administrativo, hablan, mayoritariamente, de prohijamientos, mientras que los codificadores utilizan exclusivamente el término de adopción. Pensamos, sin embargo, que, como hemos dicho, tal distinción responde a una actitud a priori de los codificadores, quienes parecenestar específicamente interesados en demostrar la diferenciación de ambos términos y en dejar fuera de la regulación civil la práctica de prohijamiento que hasta entonces se estaba dando -el prohijamiento de expósitos-. La cuestión no es sencilla, porque el examen de los reglamentos nos proporciona ejemplos que permiten abonarlas dos interpretaciones: encontramos así desde utilizaciones en las que se hace evidente la falta de rigor técnico, hasta otras que, siendo mucho más precisas, siguen uniendo prohijamiento y adopción. El primero de estos ejemplos sería el denominado Reglamento de Policía de Expósitos de $1796^{8}$, que utiliza ambos términos como equiva-

\footnotetext{
${ }^{6}$ Partida 4 a , Tít. VII, ley VII. Utilizamos la edición de Gregorio López, t. II, Compañía General de Impresores y Libreros del Reino, Madrid, 1844.

${ }^{7}$ En la literatura y prensa de la época se pueden encontrar a diario ejemplos de su utilización indistinta, en un sentido figurado: "La comisión en este artículo hace responsable al que reimprima un papel, porque el que hace esto con un escrito, lo prohija, lo adopta" (El Espectador, Madrid, 6 de febrero de 1822, p. 3); "Orden y moderación gritan, pero no el orden que prohija la razón, ni la moderación que se halla en la esfera de las virtudes" (El Revisor semanal, n 12, 18 de mayo de 1823, p. 4); "La comisión prohija el privilegio electoral de nombrar a los cien vecinos más ricos de cada pueblo" (El Español, nº 71, Madrid, 10 de enero de 1836, p. 2); "Acaso no pensó [el periódico] El Eco que prohijaba las ideas de Martínez de la Rosa, ni El Correo que prohijaba las doctrinas de López..." (Fray Gerundio, 25 de diciembre de 1840, p. 407).

${ }^{8}$ Cédula de 11 de diciembre de 1796, Reglamento de policía general de expósitos (t. II, pp. 270 y ss).
} 
lentes en varias de sus disposiciones: su artículo XII establece la conveniencia de que las amas de cría se queden con los niños durante sus años de infancia, si antes no son adoptados y prohijados por persona decente y honesta, que pueda darles buena aplicación y destino; el artículo XVII prescribe que esta relación entre expósitos y amas de cría se mantendrá si antes no se han hallado personas convenientes que con buenas condiciones los adopten y prohijen. En efecto, argumentando en contra de nuestra tesis, esta utilización conjunta de ambos términos, que aparecen unidos por una simple conjunción, podría tomarse como muestra de la falta de precisión técnica de los reglamentos ilustrados. Sin embargo, en el segundo ejemplo, que paradójicamente es también el que más cercano está temporalmente a los codificadores, se hace más difícil achacar a las carencias técnicas el que prohijamiento y adopción aparezcan unidos: así,en el extremo de la horquilla temporal elegida encontramos la Ley General de Beneficencia de 1849, en la que el procedimiento para efectuar prohijamientos, regulado con una cierta precisión, incluyecomo requisito el otorgamiento de escritura pública de adopción legal ${ }^{9}$.

Más allá de la regulación legal, son los instrumentos de aplicación del derecho, las series documentales sobre cuyo análisis se basa este trabajo, los que aportan el principal apoyo a la tesis de falta de distinción entre adopción y prohijamiento: en un considerable porcentaje de las escrituras notariales de prohijamiento o adopción de expósitos ambos términos se utilizan de forma absolutamente indistinta, si bien, justo es decirlo, con predominio del primero. Además, los ejemplos de utilización del término adopción como sinónimo de prohijamiento no se circunscriben a las escrituras de una época concreta, o de un escribano determinado, sino que aparecen a lo largo de toda la horquilla temporal de este trabajo ${ }^{10}$. El análisis detenido del contenido de estas escrituras es concluyente en el sentido de que no deja ver ninguna diferencia respecto a las que incluyen exclusivamente el término prohijamiento o

\footnotetext{
${ }^{9}$ Art. 87: "Las prohijaciones se harán igualmente por autoridad del mismo señor teniente alcalde, y su acuerdo lo trasladará el Director al escribano para que otorgue la escritura de adopcion legal de la que los interesados entregarán un tanto en la Direccion que se archivará". Ley General de Beneficencia, de 20 de junio de 1849. Publicada el 24 de junio de 1849, Gaceta núm. 5398. Disponible en www.boe.es/datos/pdfs/BOE/1849/5398/A00001-00002.pdf

${ }^{10}$ Por citar sólo algunos ejemplos, junto a otros que veremos aparecer cuando procedamos a analizar la estructura de las escrituras, encontramos el caso más antiguo de los aparecidos en una escritura de prohijamiento de 1708: "Los ottorgantes por el mucho amor y cariño que tienen a la dicha María Rodríguez por haverla criado dese su tierna hedad y no ttener ottros hixo ni herederos la quieren prohixar declarandola en la mexor forma que aya lugar en derecho por su hixa adoptiva y prohixada" (Escritura de prohijamiento de María Rodríguez, otorgada por Francisco López y María García el 26 de junio de 1708. ARCM, Fondos de la Inclusa, Legajo 8.495/1); el postrero, en 1852: "Otorgan que adoptan y reciben por hija á la espresada Cirila de San Antonio sin dependencia del Establecimiento á que corresponde, y en tal concepto se obligan desde éste dia á cuidarla, mantenerla y tenerla en su casa y compañía y estimarla cual si fuese hija suya procreada constante su matrimonio..." (Escritura de prohijamiento de Cirila San Antonio, otorgada por Nicolás Hernández y Juana Insausti el 2 de diciembre de 1852. ARCM, Fondos de la Inclusa, legajo 8.398/3).
} 
prohijación: ni en las cláusulas, ni en las condiciones, ni en las garantías, se aprecia ningún elemento diferenciador.

\section{Las escrituras de prohijamiento o adopción}

Los instrumentos formales de adopción que hemos encontrado en los Fondos de la Inclusa conservados en el ARCM para el periodo considerado en este trabajo son 319 escrituras de prohijamiento o adopción.

Estas escrituras están repartidas en siete legajos distintos, agrupadas bajo un criterio fundamentalmente cronológico, aunque hay numerosos encabalgamientos de fechas entre los distintos legajos ${ }^{11}$. Las series que hemos encontrado no parecen estar completas, presentando numerosas lagunas de mayor o menor amplitud. Por ello resulta problemático dar datos precisos sobre la frecuencia de aparición de prohijamientos; sin embargo de lo cual pensamos que el volumen total resulta lo bastante considerable como para permitirnos ofrecer algunos datos.

Las mayores frecuencias se sitúan sin lugar a dudas en las décadas centrales del siglo XVIII: a partir de 1725-30, cuando sólo de un lustro tenemos nada menos que 61 casos, la frecuencia es de unos 30-40 casos por década; a partir de 1770 las series aparecen más discontinuas. Para la primera mitad del siglo XIX nos encontramos con el problema contrario: series más completas — salvo algún hueco claro, como el de de 1808 a 1814, los años de la invasión francesa-, pero frecuencias mucho menores: entre los 10 y 20 casos por década.

Tal vez el dato más interesante sea el de que en 1852 cesan de repente los prohijamientos: de ese año en adelante no hemos podido encontrar, a pesar de haber registrado con exhaustividad los fondos del Archivo, ni una sola escritura de prohijamiento. Gracias a otro tipo de documentación - fundamentalmente las series de instancias de obligación de entrega de niñas del Colegio de la Paz, que hemos visto crecer progresivamente desde 1835-, podemos inferir que, a partir de 1852, y coincidiendo con un cambio administrativo - la vuelta de la Junta de Damas a la gestión de estos establecimientos tras el paréntesis de 1841-1850, en que fueron gestio-

\footnotetext{
${ }^{11}$ Hemos hallado estas escrituras en siete legajos distintos de los dispersos Fondos de la Inclusa del ARCM: legajo 8.495/1 (con la descripción "Escrituras de Prohijamiento 1708-1767"); legajo 8.427/5 ("Escrituras de Prohijamiento 1725-1728"); legajo 8.349/3 ("Escrituras de Prohijamiento 1743-1755"); legajo 8.409/2 ("Escrituras de Prohijamiento de Expósitos 1751-1783"); legajo 8.397/2 (denominado "Registro de Prohijamientos 1797-1849"); legajo 8.356/13 ("Escrituras de Prohijamiento de Expósitos 1842-1847”), y legajo 8.398/3 (“Escrituras de Prohijamiento de Expósitos 1851 y 1852”). Además de estas signaturas principales, hemos podido rastrear documentación relativa a algunos de estos prohijamientos, y a otros de los que no ha quedado archivada la escritura formal, en varios legajos dispersos, descritos como "Comunicaciones de entregas de niños con dependencia" para diferentes años: se trata de los legajos $8.341 / 1,8.598 / 3,8.510 / 11,8.453 / 4,8.449 / 1$ y $2,8.349 / 7,8.397 / 1,8.513 / 2,8.423 / 4$, $8.347 / 3$ y $8.416 / 13$. Quede aquí mi agradecimiento a las archiveras Ma Jesús Contreras, Marina Yrache y Teresa Flores, que me facilitaron sobremanera la localización de estos legajos.
} 
nados por las Juntas Municipales liberales- la Inclusa y la Paz, gestionadas ambas por dicha Junta de Damas, rehúsan conceder prohijamientos de sus pupilos, que suplen por las entregas de menores por la vía administrativa, una opción que hasta el momento coexistía con los prohijamientos por vía notarial y que desde la década de $\operatorname{los} 30$ aparece claramente favorecida por la institución ${ }^{12}$.

El prohijamiento formal de expósitos, realizado por vía notarial, aparece así como un procedimiento relativamente poco frecuente, pero no por ello raro ni mucho menos «inexistente», como afirmaron los codificadores y sigue asumiendo la historiografía. $\mathrm{Su}$ escasa frecuencia no lo hace, al menos a nuestros ojos, menos interesante, sino más bien al contrario, dado que se presenta como el negativo, la piedra de contraste de toda una serie de procedimientos de entrega y recepción de niños expósitos mucho más frecuentes: ya sean las entregas informales, que obviamente existían en una dimensión infinitamente más grande, aunque por su propia naturaleza apenas tengamos constancia de las mismas, como las entregas realizadas por vía administrativa, que aparecen en un determinado momento de nuestro periodo, y que terminarán, como hemos dicho, por absorber por completo la vía notarial, teniendo como efecto secundario el de oficializar una buena parte de las entregas sumergidas. Los prohijamientos aparecen así como la punta del iceberg de todos estos procedimientos, que podríamos calificar, en términos generales, de procedimientos de redistribución institucional de menores. Sus límites nos marcan las líneas de recorte final de estas prácticas.

Incluso desde una óptica puramente técnica, el acercamiento a estas escrituras nos ofrece una gran cantidad de información de enorme interés y precisión, en relación con el propio concepto de prohijamiento y adopción y sus rasgos delimitadores, el contenido asistencial y patrimonial, las obligaciones tanto para prohijantes como para prohijados, así como aspectos más cercanos a la órbita subjetiva como son las motivaciones de los prohijantes. Todos estos aspectos, así como el modo en que evolucionan en la amplia horquilla temporal de este trabajo, resultan tanto más interesantes cuanto que es por el contrario bien poco, o nada, lo que conocemos sobre este tipo de relación.

\section{La progresión cuantitativa}

Como ya dijimos, la pretensión de dar datos precisos sobre la frecuencia de aparición de prohijamientos atendiendo a las series encontradas en el ARCM tras el vaciado sistemático y exhaustivo de éste, resulta problemática, en cuanto las series que

\footnotetext{
${ }^{12}$ El de las entregas de niñas con dependencia del Colegio es un mundo inexplorado, a pesar de sus enormes dimensiones: la ingente documentación del Colegio de la Paz sobre estos expedientes arroja cifras anuales que varían entre el medio centenar a mediados de los 20 , hasta alcanzar picos de más de 80 entregas anuales —documentadas - a partir de 1834. En una próxima publicación procederemos a analizar este fenómeno, que muestra numerosas vinculaciones - no sólo funcionales, sino también formales- con los prohijamientos.
} 
hemos encontrado no parecen estar completas, presentando numerosas lagunas de mayor o menor amplitud. Los datos que aquí ofrecemos deben, por lo tanto, entenderse con precaución.

En primer lugar, nuestros datos confirman la hipótesis presente en la bibliografía existente sobre casas de expósitos durante estas décadas, en relación con la progresión inversa de los prohijamientos en los siglos del tránsito de la modernidad a la contemporaneidad: nuestra horquilla temporal nos permite afirmar que, en efecto, los prohijamientos eran más frecuentes en el siglo XVIII que en el XIX. En concreto, las décadas centrales del siglo XVIII muestran unas cifras muy considerables, con el mayor pico en el lustro de 1725-30, en el que están fechados nada menos que 61 casos. A partir de esas fechas, la frecuencia se mantiene en niveles relativamente importantes, de unos 30-40 casos por década. A partir de 1770 las series aparecen más discontinuas; el brusco descenso apreciable en la curva no se debe interpretar por lo tanto de manera absoluta, siendo la razón principal la interrupción de las series documentales: en concreto, entre 1772 y 1780 hay una laguna, siendo años de los que no tenemos ni un solo caso; la misma situación se repite entre 1783 y 1790. A falta de cambio alguno en la legislación o en la administración de los establecimientos, ninguna hipótesis puede explicar de forma razonable ese drástico descenso, que se debe a la citada discontinuidad documental. Sin embargo, los breves paréntesis de los que sí nos ha llegado documentación sí nos permiten afirmar que, sin llegar al radical descenso mostrado por la curva, los ritmos han descendido, apareciendo una tendencia regresiva que se mantendrá con el cambio de siglo.

Trataremos a continuación la evolución cuantitativa de los prohijamientos escriturados en el periodo que se abre con la toma de control de la Junta de Damas sobre la gestión de la Inclusa y el Colegio de la Paz, en 1801, hasta 1852, fecha en que los prohijamientos de niños expósitos desaparecen de forma absoluta. Las series halladas revelan unas frecuencias muy modestas durante todo el periodo, tanto que son casi inexistentes durante los primeros quinquenios, para luego ir aumentando de forma progresiva.

El número de prohijamientos, ya escaso por sí a principios de siglo, desciende poco a poco hasta 1820 — sin duda las penurias derivadas de la Guerra de la Independencia, así como las crisis de subsistencia inmediatamente posteriores pueden estar entre las causas de tal descenso-, periodo en el que la frecuencia empieza a remontar, conociendo una relativa explosión en la primera mitad de la década de los 30. Una de las razones de esta progresión tan acusada puede estar en la labor propagandística de la Junta de Damas, que a finales de la década de los 20 hizo aparecer en los periódicos diversas noticias sobre el estado calamitoso de la Inclusa y el Colegio de la $\mathrm{Paz}^{13}$; en general, la activación de la labor de la Junta en relación con las

\footnotetext{
${ }^{13}$ De ello nos informan precisamente unos prohijantes, que en su memorial de solicitud afirman estar
} Deseosos de aliviar en lo posible la grande carga y gastos que tiene sobre si la Real Casa Ynclusa de 
niñas del Colegio de la Paz, así como la mejora relativa de las condiciones de vida en la capital serían las principales razones de este aumento en los prohijamientos. El descenso tan radical que se observa entre 1836 y 1840 pensamos que se puede deber al aumento simétrico de otra forma de entregas de niños: las entregas con dependencia del Colegio, formalizadas mediante una simple instancia, y de las que nos dan abundantísima noticia los legajos del Colegio de la Paz de aquellos años.

El progresivo auge de estas entregas administrativas constituye seguramente también el marco en que debemos entender la interrupción definitiva de las series en torno a 1851. Sin embargo, 1851 es una fecha clave por varias razones. La más importante, sin duda, es la publicación del proyecto de Código Civil, el denominado proyecto García Goyena, que, a diferencia de proyectos anteriores, incluye una regulación de la adopción. La fecha de 1851 es también clave para la Inclusa y el Colegio de la Paz, porque marca el momento en que la gestión de esos establecimientos pasa de nuevo de manos de la Junta Municipal de Beneficencia, que la había detentado en el decenio anterior, a la Junta de Damas de Honor y Mérito, quien había sido su gestora, salvando ese paréntesis de diez años, desde 1801. Todas estas razones pesaron, sin duda, en el cese de los prohijamientos escriturados.

\section{La estructura de las escrituras}

Las escrituras tienen una forma tradicional, en la que podemos distinguir las siguientes partes principales:

\section{El proemio}

En esta parte aparecen los datos personales — nombre, vecindad, estado civil, modo en que comparecen ante el notario- de los comparecientes. En cuanto a quiénes comparecen ante el notario para otorgar la escritura, en la mayor parte de las escrituras son sólo los prohijantes, aunque en alguna época — de 1744 a 1762— figuran como comparecientes el Administrador de la Casa de Niños Expósitos por una parte, y por la otra los prohijantes.

\section{El memorial de solicitud}

Incluye la declaración de los prohijantes en relación con las circunstancias del acto de prohijamiento, en la que usualmente se hace constar la relación que les une

esta Corte con el numero escesivo de niños y niñas que hay en ella (sobre cuyo particular se han hecho algunas invitaciones en los periódicos de esta Capital). Escritura de prohijamiento de María Dolores Casimira Ruperta, otorgada por José Amezcua y Paula Jorge el 18 de enero de 1828, ARCM, Fondos de la Inclusa, legajo 8.397/2. 
con el prohijado: si éste está en su domicilio, y desde qué edad; si lo han criado, etc.; en caso de que se prohije un niño que no ha estado en la familia de los prohijantes, las razones por las que se ha tomado la determinación de prohijar un niño de la Inclusa o del Colegio de la Paz.

También en esta parte, en las escrituras más antiguas — hasta 1772— se hace constar que el o los otorgantes cuentan con el consentimiento del Administrador: habiendo tratado con el Administrador; pasaron a dicha Real Casa y trataron con el Administrador de esta Real Casa; han pedido a dicho Sr. Administrador; cuia pretensión hicieron con el Sr. Rector de la Real Casa, de quien consiguieron su beneplácito y licencia para ello ... La institución, encarnada en sus administradores, se hace presente en el acta notarial del prohijamiento, además del caso extremo visto con anterioridad, en que la institución comparece como tal en el otorgamiento notarial. Es crucial el modo en que esa presencia institucional desaparece en las escrituras de las últimas décadas del siglo XVIII, para no volver a reaparecer: a partir de entonces, las escrituras sólo ocasionalmente hacen referencia a los administradores de los establecimientos ${ }^{14}$, pero en ningún caso como comparecientes o consentidores expresos de la relación adoptiva.

Como parte de esta declaración suele aparecer, también, una parte más cercana a la esfera subjetiva: la expresión de las motivaciones del acto. Entre los principales motivos que se citan aparecen la misma tenencia del menor - Hacen presente que hace siete años que tienen en su poder a Josefa del Río, que sacaron de la Inclusa; Se halla con un niño en su poder llamado Pablo María Cruz-; parecido a esa tenencia, pero más preciso, es el haber ejercido la crianza del menor; a continuación, y derivado de lo anterior, el cariño o afecto que estas dos situaciones han hecho nacer; el dolor que produciría la separación por tener que dejar al menor. En un segundo nivel de frecuencia, aparece como motivación la ausencia de hijos legítimos - por no tener como no tienen al presente hijos algunos ${ }^{15} \mathrm{o}$, en otra formulación, aparentemente sinónima, la carencia de sucesores: en consuelo de la pena con que se hallan opresos, por no haver tenido dicha sucesión $n^{16}$. Mucho más raramente aparecen otras

\footnotetext{
${ }^{14}$ A partir de 1800, el consentimiento a la pretensión de prohijamiento del órgano que tiene la tutela del menor lo presta la Junta de Damas, encargada de la dirección de la Real Inclusa de Madrid y el Real Colegio de Nuestra Señora de la Paz. Sólo en casos aislados se recoge ese consentimiento expreso en la escritura: Solicitando les concediese la gracia de admitirla en su casa y compañía como por vía de prohijamiento, y la Junta precedidos los informes oportunos ha accedido a sus pretensiones... Escritura de prohijamiento de María Gregoria Joaquina, otorgada por Juan Paluche y Catalina González el 22 de agosto de 1833. ARCM, Fondos de la Inclusa, legajo 8.397/2. En el expediente sí que aparece regularmente este consentimiento, que se inserta el oficio del Rector al propio notario, en el que se comunica la concesión de la solicitud por parte de la Junta, y con el objeto de que vaya disponiendo lo conveniente para formalizar la correspondiente escritura.

${ }^{15}$ Escritura de prohijamiento de Romualdo Ángel, otorgada por Bartholomé Gil y Andrea Morales el 10 de diciembre de 1766. ARCM, Fondos de la Inclusa, legajo 8.495/1.

${ }^{16}$ Escritura de prohijamiento de Bernardo Anthonio Ladrón de Guebara, otorgada por Athanasio de Hevia y María Sanz el 30 de diciembre de 1749. ARCM, Fondos de la Inclusa, legajo 8.349/3.
} 
motivaciones, como las buenas cualidades del menor - _.. por tener sus buenas calidades ${ }^{17}$ —, ola piedad cristiana: por ser del servizio de Dios nuestro Señor ${ }^{18}$, que, en el siglo XIX se torna caridad, o incluso en algún caso toma la apariencia de colaboración con la función benéfico-asistencial de las instituciones de donde proceden los menores:

Deseosos de aliviar en lo posible la grande carga y gastos que tiene sobre si la Real Casa Ynclusa de esta Corte con el numero escesivo de niños y niñas que hay en ella ${ }^{19}$; deseando vivamente adoptar por hija ó prohijar a la expósita..., con el laudable objeto de procurar su buena educación y mejorar a ser posible su suerte, prometiéndose de esta manera una colocación más ventajosa para su día, guiados de estos caritativos sentimientos de amparar a la horfandad y hacer un bien... ${ }^{20}$.

Por supuesto, todos estos motivos pueden aparecer mezclados en diferentes combinaciones: afectos, intenciones caritativas y pragmatismo son partes de un conjunto.

\section{El otorgamiento}

El otorgamiento es la parte más importante de la escritura a nivel formal, y que consecuentemente presenta rasgos formularios, con relativamente escasa variación según el escribano. Presentamos a continuación los rasgos comunes a todas, para luego detenernos en las peculiaridades que presenta cada una de las series salida de la mano de cada escribano diferente.

La fórmula invariablemente se inicia con la declaración principal, por la que el o los prohijantes otorgan que prohijan al niño o niña: reciben y prohijan, dan por prohijado, reciben en adopción son algunas de las fórmulas más utilizadas. En las series de dos notarios de la primera mitad del XVII (las firmadas por Lorenzo Sendín y Joseph Moraleja ${ }^{21}$ ), la declaración principal es simplemente la de tener en su compañia como hijo propio, o incluso la más sucinta tener en su compañía. Ello hace que, desde una perspectiva meramente formal y restrictiva, estas escrituras puedan no considerarse escrituras de prohijamiento. Sin embargo, otros rasgos presentes en ellas, como la obligación de alimentos, vestido y educación, la institución de herencia y/o dona-

\footnotetext{
${ }^{17}$ Escritura de prohijamiento de Juan Antonio, otorgada por Pedro de Torres e Ynés Núñez el 17 de febrero de 1819. ARCM, Fondos de la Inclusa, legajo 8.397/2.

${ }^{18}$ Escritura de prohijamiento de Antonia María, otorgada por Juan Casa Deleyto y María Deleyto el 5 de enero de 1708. ARCM, Fondos de la Inclusa, legajo 8.495/1.

${ }^{19}$ Escritura de prohijamiento de María Dolores Casimira Ruperta, otorgada por José Amezcua y Paula Jorge el 18 de enero de 1828. ARCM, Fondos de la Inclusa, legajo 8.397/2.

${ }^{20}$ Escritura de prohijamiento de Blasa Güelves y Martínez, otorgada por Francisco Ferrán y María Antonia Mueda el 28 de abril de 1846. ARCM, Fondos de la Inclusa, legajo 8.356/13.

${ }^{21}$ Estas series se encuentran en los legajos 8.349/3, 8.409/2 y 8.495/1.
} 
ción o la obligación para el menor de permanecer en la compañía de los otorgantes, permiten considerarlas como equivalentes, o en cualquier caso como una variación del prohijamiento estricto.

\section{Las cláusulas}

\subsection{El compromiso de cuidado, alimento y educación}

Siempre en primer lugar tras la declaración de otorgamiento, y con muy poca variación literal, figura en todas las escrituras analizadas, casi sin excepción, la obligación principal: el compromiso solemne de tener bajo su cuidado y compañía, vestir, calzar y educar al prohijado. En la mayoría de los casos se especifica que esta obligación principal la desempeñarán los prohijantes como lo harían sus padres naturales.

Si la obligación de alimentos, así como la de vestido y calzado, se ha tomado literalmente de las Partidas ${ }^{22}$, y se mantiene inmutable hasta finales del periodo -en donde estas últimas precisiones desaparecen para pasar a hablar sólo de la obligación genérica de cuidados con un tinte afectivo: se constituyen en formal obligacion no solo de cuidar, tener y mantenerle en su propia casa y compañia, y estimarle como si fuese hijo habido constante matrimonio de los otorgantes ${ }^{23}$-, la obligación de educación, que no aparecía especificada literalmente en las Partidas y que es por lo tanto una precisión moderna, presenta numerosas variaciones. Así, en las escrituras de las primeras décadas del siglo XVIII, la obligación de educar se limita al adoctrinamiento religioso: doctrinar en las enseñanzas de la religión cristiana, en los misterios y preceptos de nuestra Santa Iglesia Catholica, o incluso en el temor a Dios, nuestro Señor. Partiendo siempre de este núcleo de enseñanza común, básico e inmutable, a partir de 1744, comienzan a precisarse otros contenidos, que además se manifiestan de forma segregada por razón del sexo: para los varones, esas otras enseñanzas pueden ser leer y escribir y contar, o bien el desempeño de un oficio; numerosos escribanos incluso recogen la obligación de proporcionar estudios de Gramática y demás estudios maiores, si los quisiese ${ }^{24}$. Sin embargo, las enseñanzas

\footnotetext{
${ }^{22}$ Partida 4a, Tít XIX: Cómo deben los padres criar a sus hijos y otrosí de cómo los hijos deben pensar en los padres cuando les fuere menester, ley II: Y la manera en que deben criar los padres a sus hijos $y$ darles lo que les fuere menester, aunque no quieran, es esta: que les deben dar que coman y que beban, y que vistan y que calcen y lugar donde moren y todas las otras cosas que les fueren menester, sin las cuales los hombres no pueden vivir, y esto debe cada uno hacer según la riqueza y el poder que hubiere, considerando siempre la persona de aquel que lo debe recibir, y en qué manera lo deben esto hacer.

${ }^{23}$ Esta fórmula aparece en la última serie de escrituras, redactada por el notario José María Garamendi entre 1846 y 1852. ARCM, Fondos de la Inclusa, legajos 8.398/3 y 8.356/13.

${ }^{24}$ Llama la atención esta mención a la obligación de dar estudios superiores a los prohijados, tanto más cuanto que apenas un siglo antes, una Pragmática había prohibido expresamente que se ofreciera este tipo de estudios en las casas de expósitos: Mandamos que no pueda haber estudios de Gramática en los hospitales donde se crían niños expósitos y desamparados; y que los administradores y superintendentes tengan cuidado de aplicarles a otras artes, y particularmente al exercicio de la marinería, en que serán
} 
para las niñas son de otro cariz: varrer, guisar, coser y demás mugeriles egercicios correspondientes a su esfera, o, simplemente los oficios mugeriles. En alguna escritura antigua de prohijamiento de una niña aparece, asimilada a la puesta en oficio de los varones, la obligación de poner a la niña a servir: $y$ siendo de edad competente ponerla en casa christiana, y decente a servir ${ }^{25}$. En las escrituras del siglo XIX, en las que desaparece por lo general la mención al adoctrinamiento religioso, así como la diferenciación por sexos para esta obligación formativa, se especifica un objeto más general para estas enseñanzas: el que se eduque al menor en tal conformidad que pueda ser útil a la sociedad y sirva a Dios y el Rey, según su sexo y facultades ${ }^{26}$.

\subsection{Las obligaciones patrimoniales}

A continuación de estas obligaciones básicas se introducen las obligaciones adicionales, de contenido eminentemente patrimonial y que presentan una mucha mayor variación de una escritura a otra: aquí figuran las instituciones de herencia o de dote.

\subsubsection{La institución de herencia}

La mayor parte de nuestras escrituras incluyen la institución del prohijado como heredero forzoso y universal de los bienes de los prohijantes: hasta 1840, éste es el caso en el $80 \%$ de las escrituras. La situación se invierte a partir de 1841, momento en el que las escrituras dejan de recoger esta institución de heredero. Más adelante trataremos de aportar una explicación para esta transformación; por el momento, interesa destacar que, en la mayor parte del periodo, la institución de heredero forzoso y universal se considera central en la adopción, hasta el punto de que prohijamiento y herencia parecen entenderse, según algunas apreciaciones incluidas en las propias escrituras y en documentos relativos a los expediente ${ }^{27}$, como intrínsecamente unidos.

muy útiles por la falta que hay en el Reino de Pilotos. Pragmática de 10 de febrero de 1623, recogida en la Novísima Recopilación, Libro VII, Tít. XXXVVII, Ley II. La preferencia por la enseñanza de oficios útiles para el Reino, y en especial de aquellos sobre los que se había detectado una carencia, muestra ya a las claras la implicación estatal en controlar el destino de los expósitos, marcando incluso líneas macro de aplicación de los niños a determinados oficios mal servidos en el momento.

${ }^{25}$ Escritura de prohijamiento de Benitha Raymunda de León, otorgada por Matheo Pillo y Francisca Núñez el 20 de junio de 1764. ARCM, Fondos de la Inclusa, legajo 8.409/2.

${ }^{26}$ Escritura de prohijamiento de Tadea Simona Acedo, otorgada por Josef Mora y Juliana Alconada el 1 de abril de 1815. ARCM, Fondos de la Inclusa, legajo 8.397/2.

${ }^{27}$ En un documento recogido en un expediente de prohijamiento de 1833, en el que se produce un conflicto al retractarse los prohijantes de una primera escritura en la que hacen la institución de heredero, el notario afirma lo siguiente: Por el mero hecho de Prohijar á la Niña, esta queda declarada por heredera de ambos, en términos que si muere el Marido se hace dueña de lo que a él corresponde, y lo mismo sucederá si muere la mujer; en lo que ésta no manifiesta su conformidad. El Escribano no puede alterar de modo alguno lo que está establecido, y es como dejo dicho, que la niña queda heredera según fallezcan los prohijantes. Expediente de prohijamiento solicitado por Manuel Sillero y María Cecilia Ravelli, documento de 1 de marzo de 1833. ARCM, Fondos de la Inclusa, legajo 8.598/3. 
En ocasiones aparece claro que la herencia, e incluso el mismo acto de prohijar, se subordina a la no existencia de hijos legítimos. La institución de herencia se hace depender de la ausencia de hijos legítimos de los prohijantes, salvo en los primeros años de 1700, en donde no aparece esa condición pero sin embargo se especifica invariablemente que la herencia será en la conformidad que heredan los que se prohijan - algo difícil de concretar, ya que ninguna disposición de la época se refiere a esa especificidad hereditaria-. Muy pronto, sin embargo, las escrituras que se refieren a la institución de herederos universales precisan inmediatamente a continuación que ello sólo tendría efecto en el caso de que no existan hijos legítimos. En las de un escribano concreto, Lorenzo Sendín (escrituras de los años 1725 a 1728), se especifica que si los hubiere, la herencia del prohijado habrá de entrar en el quinto de libre disposición; en otras, se hacen referencias a la mejora:

Y al tiempo de otorgar esta Escritura dixeron los otorgantes que en el caso de tener hixos de su Matrimonio que sean herederos forzosos mejorarán a la dicha... en todo lo que las leyes les permiten para que no quede defraudada la intención de los otorgantes ${ }^{28}$.

En consonancia con esto, son muy escasos los casos de escrituras en las que habiendo declarado los otorgantes la existencia de hijos legítimos se instituya herencia a favor de los prohijados: hemos contabilizado únicamente 7 casos -6 de los cuales se cuentan entre las escrituras más antiguas, de la primera mitad del XVIII-. No obstante, es posible que los casos en que se diera de hecho la coincidencia de hijos legítimos y herencia para el prohijado hayan sido bastante más numerosos que los citados; bastaría con que simplemente no se declarara la existencia de hijos —algo muy posible, al no existir obligación expresa de hacer esa declaración-, para que no los pudiéramos detectar.

La inclusión del prohijado en la herencia se mantiene como una característica de la mayor parte de las escrituras hasta casi el final de nuestro periodo - en concreto hasta 1841, en donde desaparece totalmente-. El cambio no parece que pueda deberse únicamente a la sustitución del notario adscrito a la Inclusa y Colegio de la Paz, que se produce por esas mismas fechas; unos pocos años después, cuando otro notario distinto entra en escena, las escrituras siguen sin consignar la institución de heredero, si bien añaden la consoladora mención de que, al momento de su muerte, los otorgantes donarán al prohijado todo lo que buenamente puedan y las leyes los consientan. La fecha de 1841 es clave para la Inclusa y el Colegio de la Paz, porque marca el momento en que la gestión de esos establecimientos pasa de manos de la Junta de

\footnotetext{
${ }^{28}$ Es el caso de algunas escrituras de los primeros años del XIX: vid. escritura de prohijamiento de Ana Gutiérrez, otorgada por Crisanto Claros y Dorotea Urosa el 30 de diciembre de 1805; escritura de prohijamiento de Pablo María Cruz, otorgada por Josef Prieto y Rafaela Montero el 6 de junio de 1806. ARCM, Fondos de la Inclusa, legajo 8.397/2.
} 
Damas de Honor y Mérito a la Junta Municipal de Beneficencia. La administración liberal parece optar con total claridad por un modelo de prohijamiento diferente al que se estaba practicando en la Inclusa madrileña hasta el momento. Sería sin embargo incorrecto asumir que ese nuevo modelo fuera, globalmente considerado, de menor exigencia y rigor para los prohijantes, pues al tiempo que desterraba esta obligación sucesoria abogaba con mayor fuerza y precisión por la necesidad de consignar una dote; por otra parte, añadía a las cláusulas obligatorias un nuevo compromiso, inédito hasta el momento, y que supone un paso muy importante hacia un compromiso adoptivo más fuerte: la prohibición terminante y absoluta de devolver el menor al establecimiento, con independencia de que medien o no razones que antes se consideraban «causas justas».

Además, al tiempo que desaparece de la fórmula notarial la institución de herencia aparece en las escrituras otra cláusula que al menos simbólicamente viene a suplir ésta: la obligación de entregar o devolver al prohijado, en el momento en que salga de su compañía, cualesquiera bienes que haya podido recibir mediante herencia o de cualquier otro modo mientras estuviera bajo el poder de los prohijantes. Es posible que la intención de los notarios al incluir esta cláusula fuera no tanto la de preservar unos posibles derechos patrimoniales — derechos por otra parte de ocurrencia bastante improbable - como la de reafirmar el mantenimiento de la vinculación filial original de los prohijados. Recordemos que el Proyecto de Código Civil isabelino incluía de hecho una reafirmación de la vinculación filial original: el art. 379 de este Proyecto dispone que la adopción no altera los derechos ni las obligaciones respectivas, entre el adoptado y su familia, pudiendo el hijo adoptivo tomar el apellido del adoptante, juntamente con el de su padre natural.

\subsubsection{El compromiso de dote}

El compromiso de dote, o donación de bienes diferida al momento en que los prohijados «tomen estado el que eligieren» — ya sea mediante matrimonio o profesión religiosa - aparece en un porcentaje todavía mayor que la herencia, por más que determinados escribanos —el caso de Santiago Estepar, Miguel de Llama y Diego Portal, los sucesivos «titulares» de la notaría de estos establecimientos entre 1790 y 1842 la eliminen de forma general de sus escrituras. Pero si la dote está tan extendida que aparece en más del $80 \%$ de los casos, el contenido de la misma es bastante variable, abarcando desde las donaciones indeterminadas — algunos bienes; bienes suficientes; todo lo que pudieren; lo que buenamente puedan... - hasta las más concretas, que especifican las características de los bienes muebles o inmuebles que se consignan como dote $^{29}$. El caso más generalizado en las décadas finales del XVIII es el que se-

\footnotetext{
${ }^{29}$ Es el caso de esta escritura de 1710, en la que se especifica que los otorgantes otorgan de su libre y espontanea voluntad en la mejor forma que por derecho lugar huviese, que hazen grazia y donacion
} 
ñala una cantidad determinada en dinero - usualmente 50 reales, con algunas excepciones tanto por arriba como por abajo, hasta alcanzar en varios casos los 100 ducados de vellón ${ }^{30}$ - A estas cantidades se les suma, en el caso de las prohijadas de sexo femenino, casi sin excepciones el ajuar, consistente en la cama con colchones y ropa correspondiente, así como demás trastos y axuar necesario para el adorno de un cuarto de su esfera. Los varones, salvo en unos pocos casos, no aparecen como beneficiarios de ese tipo de bienes muebles, consignándoseles únicamente la entrega monetaria. Las obligaciones de enseñanza anteriormente vistas, mucho más específicas y exigentes para los varones que para las mujeres, así como las de enseñar o poner en un oficio - enseñarle a leer, escribir y contar, y ponerle en el oficio $u$ oficios que eligiere, y enseñarle la Gramática y los Estudios mayores si a ellos se inclinare $^{31}$ - serían la evidente contrapartida de este desequilibrio. Otra posible razón es la utilidad más inmediata de las niñas para las familias: la obligación de éstas de servir en la familia de acogida o en otras familias aparece recogida en algunas de las escrituras más antiguas ${ }^{32}$.

pura, mera, perfecta e yrrebocable que el derecho llama intervibos [...] es a saber de una tierra de pan llebar de cabida de tres medidas de trigo en sembraduras que tienen y poseen en [...] = mas la mitad de un casco de bodega en termino de [...] = mas una cama de ropa como se estila en esta tierra que se compone de dos mantas de lana = dos sabanas de lienzo de casa $=$ dos almuadas de lienzo dicho = un jergón $=$ una delantera $=$ y unos palos ordinarios de cama de pino = Mas zien reales de vellón en el valor de bienes muebles, ajuar y omenaje de casa = Cuios bienes se donan a la susodicha para luego mediatanmente que tome estado. Escritura de prohijamiento de María Valle, otorgada por Juan de Moranchel y María de Viana el 8 de junio de 1710. ARCM, Fondos de la Inclusa, legajo 8495/1.

${ }^{30} \mathrm{Sin}$ embargo, esta cantidad de 100 ducados es mencionada en un expediente como el mínimo a que los prohijantes se debieran comprometer: en un oficio incluido en el expediente de prohijamiento de Juan de Dios de San Joseph, escritura de fecha 21 de junio de 1770, el Administrador afirma lo siguiente: Quando pasé a servir la administración de esta Real Casa hallé la costumbre de que mis antecesores no se detenian en prohijar qualquiera criatura siempre que los que la criavan (regularmente pobres) hacian la pretensión, unas veces, sin más formalidad que la de un asiento en el libro donde constava la Partida de la misma criatura y prohijantes y otras ante el Escrivano de la Casa, sin expresar, si tenian o no vienes algunos, de que se han originado muchos daños a estos pobres niños, privandolos de que pasen al Colegio de los Desamparados, donde se les educa, y da sus destinos correspondientes como ygualmente a las niñas ya en él, y también en el de nuestra Señora de la Paz; por lo que determiné [...] el que en lo subcesivo no tubiese efecto, sin que primero precediese información de la vida y costumbres de los que solicitan tales prohijaciones y que depositaren en la Arca de Tres Llaves (que á este fin hai en la Casa), a lo menos cien ducados para que en todo acontecimiento puedan tener estos niños algun alivio, quando llegue el caso de tomar estado y no el que queden abandonados, como há sucedido. Expediente de prohijamiento de Juan de Dios de San Joseph, solicitado por Juan Forner e Isabel García. ARCM, Fondos de la Inclusa, legajo 8.409/2.

${ }^{31}$ Escritura de prohijamiento de Juan de la Cruz Soler, otorgada por Juan de Enero y Benita Martínez el 18 de diciembre de 1760 y todas las del escribano Moraleja. ARCM, Fondos de la Inclusa, legajo 8.409/2. ${ }^{32}$ Es el caso de varias de las más antiguas: Cuios bienes se donan a la susodicha para luego mediatanmente que tome estado, con los pactos y condiciones siguientes = Primeramente, que la dicha María Valle ha de estar en compañia de los dichos otorgantes asta que tome estado sirbiendolos y asistiendolos en lo que pueda hazer, y es común y regular y a de ser su obligacion de dichos otorgantes en el dicho tiempo asta que tome estado alimentarla, vestirla, calzarla y curarla y medicinarla en sus enfermeda- 


\subsection{Condiciones}

Tras estas obligaciones por parte del o los prohijantes, se suele incluir, como condición de las mismas, la continuidad del prohijado en la relación, que no cesará salvo que medien justos motivos. La permanencia del prohijado en la compañía de los prohijantes aparece recogida formulariamente como una condición resolutoria de todas las anteriormente vistas obligaciones de los otorgantes, y suspensiva de la de entrega de la dote. Aparece en la mayor parte de las escrituras, hasta el final del periodo - a partir de 1838 desaparece tal condición-. La fórmula apenas varía con el tiempo, desde las escrituras más antiguas:

con calidad que la susodicha ha de estar premanente hasta que tome dicho estado en casa de los dichos otorgantes y si se saliere de ella antes de tomar dicho estado por algun azidente sin consentimiento de ellos a de ser nula dicha manda de dichos 40 ducados que no se les a de poder obligar a la paga de ellos ${ }^{33}$,

hasta las de épocas más avanzadas:

en la inteligencia de que ésta ha de permanecer en su Casa y compañia y no se haya separado de ella por justos motivos que haya dado, porque en otro caso cesarán estas obligaciones y daran cuenta a quien corresponda para que no se distraiga ni pierda la insinuada niña ${ }^{34}$.

La permanencia de los menores en la casa y compañía de la familia de acogida queda estrechamente vinculada a la obligación patrimonial de entrega de las cantidades prometidas como dote:

Entendiendose todo lo aquí referido con tal que el mencionado niño no se ausente de la casa y compañia de los dichos dos otorgantes, sin darle estos para ello motibo, porque en tal caso han de quedar los susodichos sin obligación alguna ${ }^{35}$.

des. A que se obligan. Es condición que la dicha María del Valle no ha de pedirles por si ni por otra persona a los susodichos soldadas ni intereses algunos por razón del dicho serbizio (Escritura de prohijamiento de María Valle, otorgada por Juan de Moranchel y María de Viana el 8 de junio de 1710. ARCM, Fondos de la Inclusa, legajo 8.495/1); y siendo de edad competente ponerla en casa christiana, $y$ decente a servir. Escritura de prohijamiento de Benitha Raymunda de León, otorgada por Matheo Pillo y Francisca Núñez el 20 de junio de 1764. ARCM, Fondos de la Inclusa, legajo 8.409/2.

${ }^{33}$ Escritura de prohijamiento de Matthias Gorvea, otorgada por Francisco Antonio de la Cruz y María de la Concepción el 27 de agosto de 1710. ARCM, Fondos de la Inclusa, legajo 8.495/1.

${ }^{34}$ Escritura de prohijamiento de Lucía Andrea, otorgada por José Mata y Gregoria Berrio el 23 de diciembre de 1839. ARCM, Fondos de la Inclusa, legajo 8.397/2.

${ }^{35}$ Escritura de prohijamiento de Juan de la Cruz Soler, otorgada por Juan de Enero y Benita Martínez el 18 de diciembre de 1760. ARCM, Fondos de la Inclusa, legajo 8.409/2, y todas las de los escribanos Alderete, Sendín, Moraleja, Estepar, y Llama. 


\section{Garantías}

Cerrando la parte dispositiva, aparecen los medios por los que los otorgantes se obligan al cumplimiento de las obligaciones anteriormente enumeradas. La formulación básica es la que alude a la responsabilidad con su persona y bienes - en el caso de los varones - o, para las mujeres, sólo con los bienes, presentes y futuros, habidos y por haber. Igualmente se mencionan las medidas de cumplimiento forzoso, para lo que se da poder «a las justicias y jueces» para ejecutar tal cumplimiento. Estas garantías aparecen en todas las escrituras casi sin excepciones, desde las más antiguas

... y consienten se les apremie a su cumplimiento, de cuya obligacion hizieron de sus personas y vienes y dieron poder cumplido a las Justicias y Juezes de su Magestad... ${ }^{36}$

hasta las últimas del periodo:

o de lo contrario consienten ser apremiados por todo rigor de derecho, con todas las costas, daños y perjuicios que se la causen en su exacción cuya liquidación defieren relevandola de otra prueba. Ygualmente se obligan a no reclamar esta Escritura ni alegar excepción aunque les faborezca, y si lo hiciesen consiente no ser oídos judicial ni extrajudicialmente, y sea visto haberla probado y ratificado; y para su cumplimiento dan poder a justicias competentes, que si lo hagan cumplir y renuncia las leyes y derechos de su favor ${ }^{37}$.

\section{Renuncias}

Finalmente, las renuncias, o cláusulas formales de distinto contenido mediante las que se renuncia a facultades legales; así, el compromiso de no reclamar el contenido de la Escritura de ninguna forma, que de nuevo aparece a lo largo de toda la horquilla temporal en que se distribuyen estas escrituras:

... en cuia virttud la habremos por firme, y no contradiremos, ni reclamaremos en ningun tiempo, con mottivo ni causa alguna, aunque la tengamos lexittima para ello, y si lo huvieremos consenttimos no ser oydos en juicio, $n i$ fuera deel; antes si repelidos y desechados, como no parttes, y que por el mismo echo se enttienda aprovarla y rattificarla de nuebo, y añadir la fuerza a fuerza, $y$ conttratto a conttratto para su maior firmeza y validacion... ${ }^{38}$.

\footnotetext{
${ }^{36}$ Escritura de prohijamiento de Antonia María, otorgada por Juan Casa Deleyto y María Deleyto el 5 de enero de 1708. ARCM, Fondos de la Inclusa, legajo 8.495/1.

${ }^{37}$ Escritura de prohijamiento de Juliana Dominga Lerraux y Sánchez, otorgada por Ramón de Arriva y Josefa Lorente el 22 de enero de 1841, y todas las del escribano Juan José Portal. ARCM, Fondos de la Inclusa, legajo 8.356/13.

${ }^{38}$ Escritura de prohijamiento de Bernardo Anthonio Ladrón de Guebara, otorgada por Athanasio de Hevia y María Sanz el 30 de diciembre de 1749. ARCM, Fondos de la Inclusa, legajo 8.349/3.
} 
Ygualmente se obligan a no reclamar esta Escritura ni alegar excepción aunque les faborezca, y si lo hiciesen consienten no ser oídos judicial ni extrajudicialmente, $y$ sea visto haberla probado y ratificado. ${ }^{39}$

También en este apartado aparecen las renuncias expresas a cualquier ley o derecho que se pueda esgrimir a su favor y en contra de tales obligaciones; entre éstas últimas se incluyen, casi siempre, las renuncias específicas de las mujeres casadas a cualquier ley o derecho que les pudiera competer. Entre ellas, las escrituras más antiguas citan expresamente las leyes romanas y el derecho histórico castellano; así, se hace constar que la prohijante, además de a las leyes generales, renuncia

... las del Veleyano Senatus Consultus Emperador Justiniano, nueva y antigua Constitución, Toro, Madrid, y Partida y demás del fabor de las mugeres de cuyo auxilio y remedio fue havisada por mi el Escribano, y como enterada de ellas las renunció y apartó de su favor para no aprovecharse de ellas ${ }^{40}$.

Esencialmente, estas leyes disponían que la mujer no puede obligarse por fiadora del marido, aunque sea en su provecho; igualmente, que en las obligaciones contraídas mancomunadamente por los cónyuges, la mujer no puede quedar obligada, salvo en el caso de que se pruebe que de la deuda resulte ella beneficiada. A partir de la publicación de la Novísima Recopilación, los notarios obviarán la cita de las leyes romanas, para recoger únicamente la Ley 61 de Toro ${ }^{41}$.

Relacionado con esta última renuncia por parte de las esposas, en una buena parte de las escrituras se incluye la declaración de la mujer de haber hecho el otorgamiento de su propia y libre voluntad: que no ha sido seducida ni atemorizada por su marido, ni otra persona en su nombre, sino que lo verifica de su libre voluntad.

\section{Autorización}

En último lugar se consignan los datos sobre los testigos presentes - siempre en número de tres-, el notario que da fe, el lugar y fecha de la escritura y por último las firmas de los prohijantes y de todos los citados.

\footnotetext{
${ }^{39}$ Escritura de prohijamiento de Juliana Dominga Lerraux y Sánchez, otorgada por Ramón de Arriva y Josefa Lorente el 22 de enero de 1841, y todas las del escribano Juan José Portal. ARCM, Fondos de la Inclusa, legajo 8.356/13.

${ }^{40}$ Escritura de prohijamiento de Luis Juan Camilo Monasterio, otorgada por Diego Gavaldon y Cathalina Baraona el 19 de junio de 1765. ARCM, Fondos de la Inclusa, legajo 8.409/2.

${ }^{41}$ Precisamente sobre esta Ley 61 de Toro centró su tesis de Doctorado Gumersindo de Azcárate, con un análisis crítico de la misma, atendiendo a su contexto histórico-jurídico. Vid. G. de Azcárate, Juicio crítico de la ley 61 de Toro, exponiendo sus motivos, su objeto y su conveniencia, Madrid 1869. $2^{\mathrm{a}}$ ed. en Revista de Ciencias Jurídicas y Sociales, I, 1918, pp. 12-22. Cfr. L. García de Valdeavellano, Seis semblanzas de historiadores españoles, Sevilla, 1978, pp. 115-120.
} 


\section{Conclusiones}

Las escrituras de prohijamiento analizadas son suficientes, tanto por su número como por sus cuidadas características formales, para demostrar la vitalidad de la institución adoptiva durante los siglos XVIII y XIX, hasta las décadas inmediatamente anteriores a la codificación civil. Las obligaciones recogidas en las mismas, tanto de carácter personal como patrimonial, les confieren un nivel de exigencia que desmiente la idea, asumida por la mayor parte de la historiografía, de que los prohijamientos de expósitos son actos en buena parte informales y carentes de requisitos, en contraposición a las adopciones, que revestirían, ellas sí, un carácter formal. Por el contrario, los prohijamientos realizados en la Inclusa de Madrid demuestran que, al menos hasta 1850 , la diferenciación entre adopción y prohijamiento de expósito basada en esas características no existe; tampoco, desde luego, se puede decir que se trate de actos administrativos, opuestos a la naturaleza civil de la adopción. Los prohijamientos que hemos analizado constituyen, sin lugar a dudas, verdaderas adopciones.

Ello demuestra que la asunción por parte de los codificadores de que la institución de la adopción era una institución muerta cuando ellos la recogen, manifestando que lo hacen por inercia y por la inocuidad y posibles beneficios de la misma, era falsa o errónea. Entre las razones de este error, se podría contar la reserva con que históricamente se ha contemplado la institución de la adopción, prototipo de ficción jurídica que además encarna una posibilidad familiar alternativa al modelo cognaticio. Asimismo, el desprecio de los codificadores, lisa y llanamente elitista, hacia los prohijamientos de expósitos. Como resultado de esa visión eminentemente prejuiciosa, la perspectiva codificadora contempla la adopción como un acto eminentemente privado, despreciando enteramente los actos adoptivos realizados dentro de las instituciones caritativas y benéficas, en tanto que los considera prácticas desrreguladas o puramente administrativas.

La evolución de la institución adoptiva, orientada hacia la progresiva intervención institucional, deja bien a la vista el error de apreciación de los codificadores, así como la flexibilidad de la institución y su carácter clave en la redistribución interfamiliar de menores, un procedimiento de cuyas dimensiones y características tan poco se sabe pero que resulta clave para entender la historia de la familia en las épocas precontemporáneas. 